\title{
Exploring attitudes and practices of General Practice staff towards offers of opportunistic screening for chlamydia: a UK survey
}

\author{
Louise Wallace ${ }^{1}$, Cliodna McNulty ${ }^{2}$, Angela Hogan ${ }^{3}$ and Julie Bayley ${ }^{4}$ \\ ${ }^{1}$ Professor of Psychology and Health, Director of the Applied Research Centre Health and Lifestyles Interventions, \\ Coventry University, Coventry, UK \\ ${ }^{2} \mathrm{Head}$ of Health Protection Agency's Primary Care Unit, Microbiology Department, Gloucestershire Royal Hospital, \\ Gloucester, UK \\ ${ }^{3}$ Research Project Manager, Health Protection Agency's Primary Care Unit, Microbiology Department, \\ Gloucestershire Royal Hospital, Gloucester, UK \\ ${ }^{4}$ Senior Researcher, Applied Research Centre Health and Lifestyles Interventions, Coventry University, Coventry, UK
}

\begin{abstract}
Aim: This study applied a theory-based questionnaire to examine the behaviours and beliefs of all practice staff who may be involved in offering chlamydia screens to young people aged $15-25$ years old. We aimed to identify potential influencing factors and examine the organisational constraints, which may be amenable to change. Background: The National Chlamydia Screening Programme offers opportunistic screening to men and women between 15 and 25 years old who have ever had sexual intercourse and primary care is the second largest source of screens. In England 15.9\% of the target group were screened against a target of $17 \%$ in 2008 . Interventions to improve the frequency of offers have shown effects with volunteer practices. Methods: A survey of 85 General Practices was completed by 55 doctors, nurses and receptionists. Interviews were conducted with 12 staff from three practices. Findings: Respondents were unable to identify the national screening target. Only half record if a patient is sexually active. Half the sample had some recollection of the frequency of offers they made, with a mean of 4 per month. These were predominantly in consultations concerning sexual health. Perceived social norms are favourable to screening and respondents have strong perceived control over offering screens, including to those under 16 who are sexually active. Attitudes towards screening were positive but disadvantages and barriers related to increased pressure on practice resources for longer consultations and contact tracing. There were no differences in beliefs and practice behaviours between medical and nursing staff. Conclusions: Future interventions should be targeted at increasing the range of consultations in which offers are made, demonstrating how to make offers without increasing consultation time, providing more complete records of sexual activity, screens and results, and encouraging audit and review within the practice to promote practice wide approaches to increasing opportunistic screening.
\end{abstract}

Keywords: behaviour; beliefs; chlamydia; General Practice; health screening; practice

Received 24 December 2010; accepted 15 November 2011; first published online 7 February 2012

Correspondence to: Professor/Dr Louise Wallace, Professor of Psychology and Health, Applied Research Centre Health and Lifestyles Interventions, Coventry University, Priory Street, Coventry CV1 5FB, UK. Email: hsx201@coventry.ac.uk

(C) Cambridge University Press 2012 


\section{Introduction}

Genital Chlamydia trachomatis infection is the commonest sexually transmitted infection (STI) in England (Health Protection Agency (HPA), 2010), and rates are increasing annually, largely due to a national screening campaign and more sensitive testing. Untreated chlamydia threatens the future fertility of men and women. A significant proportion of cases, particularly among women, are asymptomatic thereby facilitating disease transmission. In order to ameliorate the increasing prevalence of genital chlamydial infection, it is essential to identify and assess methods to improve screening coverage. Indeed, mathematical modelling has indicated that significant reductions in chlamydia prevalence may be achieved through increased screening coverage (Pimenta et al., 2000) The National Chlamydia Screening Programme (NCSP), which offers opportunistic screening to men and women between 15 and 25 years old who have ever had sexual intercourse, has been implemented to increase screening rates.

In all Primary Care Trusts (PCTs) in England the current Local Delivery Plans (LDPs) had targets of $25 \%$ of the total target population (people aged 15-24 years) screened by 31 March 2009. During the NCSP pilot studies, the majority of screens were undertaken in General Practice (Department of Health, 2004; National Chlamydia Screening Steering Group, 2006). However, despite the favourable results observed in the pilot studies, in the actual programme itself, General Practice participation has been sub-optimal (Low, 2007). Furthermore, there has been recent criticism of the low uptake, and the opportunistic screening method used in the NCSP (Department of Health, 2004; National Chlamydia Screening Steering Group, 2006; McNulty et al., 2008a; 2008b).

The National Audit Office (2009) report showed that in 2007-2008 the 152 PCTs in England achieved an average of $4.9 \%$ chlamydia screening in the target population and $15.9 \%$ in the year 2008-2009. Of these $16 \%$ were performed in General Practitioner (GP) services. There is no reference to chlamydia screening in the Quality and Outcomes Framework, but many PCTs have introduced local incentives. The variability of achievement of the targets suggests there is scope for targeting resources more effectively. We report a study in practices in two PCTs, one of which had the lowest rates of screening in the West Midlands, being under 2\% against a target of $17 \%$ in the PCTs' Vital Signs Indicator at the time of the study in 2008 .

In other Western countries, such as the United States and Australia, low chlamydia screening rates have resulted in studies assessing the barriers and facilitators identified by primary care providers to their practice in offering screens, such as concerns about cost effectiveness and lack of availability of urine-based tests (Boekeloo et al., 2002), and beliefs of physicians about offering chlamydia screens (McClure et al., 2006). Cook et al. (2001) showed that beliefs of physicians are predictive of lower rates of screening of young men. Yet rates of infection have been found to be high in males attending family planning clinics (Sripada et al., 2007). Physicians were less likely to screen if they believed the prevalence of infection was very low in their practice (Cook et al., 2001).

It is plausible that interventions targeting factors such as these could increase the rates of routine chlamydia screening among young people. A small number of educational interventions have been implemented targeting primary care physicians and the correction of barriers to screening younger women. Three out of four studies in a systematic review found significantly increased screening rates between $100 \%$ and $276 \%$, while a fourth showed an attenuation of a declining rate (Ginige et al., 2007). A further study with an educational component and clinic chart prompts for at-risk women had no overall effect (Scholes et al., 2006). A cluster randomised trial of an interactive educational workshop and modified referral form in the United Kingdom showed an increase compared with controls of $33 \%$ in the numbers screened, but the study did not report the numbers of offers of screening made (McNulty et al., 2008a; 2008b).

Evidence from these studies demonstrate the possible effectiveness of interventions in increasing chlamydia screening when they are developed through detailed exploration of the factors influencing General Practice staff behaviour to offer screens in engaged volunteer practices. We proposed to study the factors influencing offer behaviour since this is the behaviour under the direct control of General Practice staff. Since offers can be made by non-clinical staff we planned to include all staff in patient contact in General Practice surgeries.

Primary Health Care Research \& Development 2012; 13: 255-268 
In addition to identifying, as previous studies have, the General Practice staffs' perceptions of the practical barriers and facilitators of providing this service, we also investigated their personal beliefs, intentions and practice behaviour using a commonly used model of voluntary behaviour.

\section{The theory of planned behaviour (TPB)}

The TPB (Ajzen, 1985) is one of the most popular psychological models used for explaining human behaviour. The TPB proposes that behavioural intentions are the most important determinants of behaviour and are a function of three considerations: beliefs about the possible consequences or other attributes of the behaviour (attitudes towards the behaviour); beliefs about the normative expectations of others (subjective norm beliefs); and beliefs about the presence of factors that can facilitate or impede the performance of the behaviours (control beliefs; see Figure 1).

Behavioural beliefs are the source of positive or negative attitudes towards the behaviour, normative beliefs are the reflection of perceived social pressure or subjective norm, and control beliefs can influence intention and behaviour. In the context of this study we might seek to influence attitude via emphasising the population benefits of screening. Social norm might be influenced by describing the strategies used by peers to undertake screening. Influencing perceived behavioural control (PBC) might be achieved by modelling how barriers can be overcome. Given actual control over the behaviour, individuals are expected to fulfil their intentions when the opportunity presents itself. Research in other domains has used this model to design behaviour change interventions, for example Hanbury et al. (2009) report a TPB intervention to increase adherence of community mental health professionals to a national suicide prevention guideline.

\section{Aims}

This study applied a TPB-based questionnaire to examine the behaviours and beliefs of all practice staff, including receptionists, and examine the organisational constraints that may be amenable to change.

\section{Method}

The study was approved by Coventry University Research Ethics Committee, and NHS ethics and trusts' Research Governance Offices (NREC 08/ H1211/57).

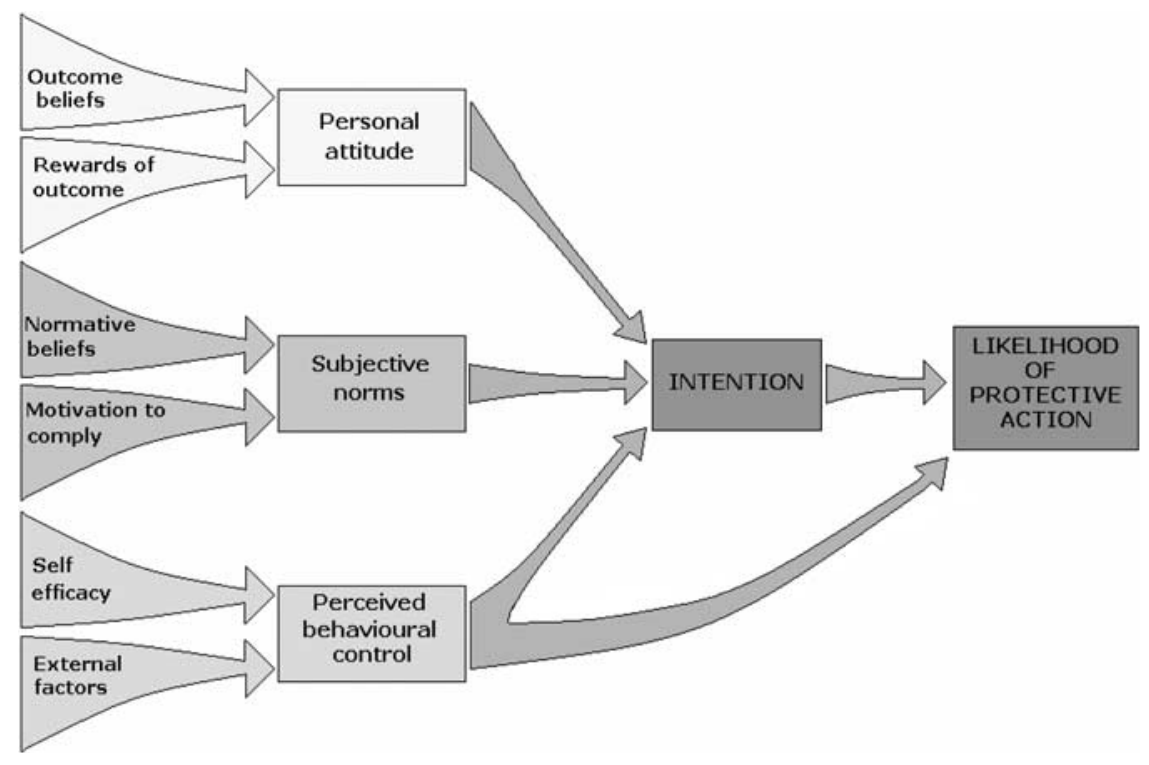

Figure 1 The theory of planned behaviour (TPB). 


\section{Procedure}

\section{Phase 1. Developing the TPB questionnaire}

To aid the development of the TPB questionnaire, interviews were conducted with staff in two General Practice surgeries identified by local sexual health stakeholders and contacted by letter. Twelve 30-min semi-structured interviews were conducted with five GPs, three practice nurses, one practice manager and three receptionists.

The interviews were recorded, transcribed and were analysed thematically to identify TPB-related constructs that were included in the questionnaire. The behaviour of interest was that practice staff would offer a chlamydia screen to all patients aged 15-24 years old who have ever had sexual intercourse, which is in line with the LDP targets. Once the questionnaire was developed it was sent to the above practice staff in Warwickshire to be reviewed, and minor changes made to improve ease of administration. The finalised questionnaire for the survey is described below.

\section{Phase 2. Determining foci for the future interventions}

Recruitment of sample: a minimum of 50 responses was required for survey validation, and to achieve spread across size of practices and their urban and rural populations. The survey was distributed by post and via an e-mailed link to a web survey to 258 staff from 85 surgeries in Warwickshire and Coventry selected at random, targeting in each surgery one General Practitioner, one nurse and one receptionist. These were returned by free post by 25 October 2008 .

\section{Measures}

\section{TPB questionnaire}

Procedures for the development of the TPB questionnaire published by Ajzen and Fishbein (1980) were followed. All items were measured on 7-point scale, and responses for each construct were averaged over items. To minimise response bias related to the order in which questions were asked, items associated with each particular construct were interspersed throughout the questionnaire. In the final analysis, all items were organised so that higher scores indicated more favourable responses.
Intentions to offer screens were assessed from responses to a single statement (eg, 'I will try to offer a chlamydia screen to every person I see in my clinics aged 16-24, who have ever had sex').

Attitudes were measured by rating on a 7-point scale the agreement with a list of advantages (eg, increased detection of positive cases, raising awareness of chlamydia) and disadvantages (eg, intrusive for patient, increase patient's anxiety). Participants were also asked whether any of their answers to these questions would be different in relation to people aged 15 who have been sexually active.

Subjective norms were measured using a 7-point scale anchored by 'completely approve'-'completely disapprove' to rate the approval level of 'most people in my practice (whose opinions I value)'; 'the most influential with regards to offering chlamydia screens to target group'; 'others outside of the surgery' (with response options including Genito-Urinary clinic, Schools/youth groups, PCT, chlamydia co-ordinator, whole population).

PBC was measured by asking participants to rate the following three statements on a 7-point scale of agreement:

\section{I feel I have full control over whether or not I offer a chlamydia screen to the target group in my surgery}

I am confident that I can offer a chlamydia screen to the target group in my surgery

I have the required knowledge and skills to offer an opportunistic chlamydia screen to the target group in my surgery

They were then asked to rate a list of 16 circumstances on a 7-point scale anchored by the 'Much Easier'-'Much Harder' bipolar adjectives. Finally they were asked to rate six barriers in the format, 'How important do you think the following barriers are to preventing you from offering a chlamydia screen to the target group?' and 'How likely they are to stop you offering a chlamydia screen to the target group?'

In each closed question section related to TBP constructs there was an open question asking for any additional comments. These comments were analysed to establish if new items should be added for future studies.

The internal reliability of subscales was tested using Cronbach's $\alpha$, and all subscales were above an acceptable level of 0.8 . 
The survey also assessed the participants' own screening behaviour, including their methods for screening, frequency of screening offers in different types of consultation, and factors influencing whether they offer screens. They were asked about how they record chlamydia screens and their estimation of the current percentage of the target group offered a screen within the last year in their practice by themselves and in the surgery as a whole. They were asked if they knew what the national screening target rate for 2008 was, and to state the target. An open question asking for additional comments to explain answers to the closed questions about personal practices used was included. Following a closed question about perceived barriers to offering screening to those 16-25 years, they were asked to comment on any differences related to people of aged 15 years. An open question was used to gain extra information about practices, and they were asked 'Do you think there are any specific advantages or disadvantages to offering chlamydia screening to people aged 15 years who have ever had sex?' At the end of the survey they were invited to respond to a general item: "Are there any other comments you would like to add about Chlamydia screening in your practice?' They were also invited to comment on the survey itself.

\section{Data analyses}

Statistical analyses were performed with SPSS version 16.0. Frequencies were calculated and qualitative sections of the questionnaire were analysed thematically. $T$-tests and $\chi^{2}$ analysis were used to assess differences in responses between General Practitioners and nurses. We examined the surveys for missing data and noted that receptionists' responses had the most missing data.

\section{Results}

\section{Practices and sample}

We received a total of 55 completed questionnaires ( 52 paper, three online) from 40 practices. Respondents included five males. Job types were 26 practice nurses, 18 General Practitioners, nine receptionists, one practice manager and one research nurse. There were 11 practices with fewer than 3000 patients, 16 with 3000-5999, 10 with 6000-8999 patients, 10 with $9000-11999$ and 8 with 12000 or more patients.

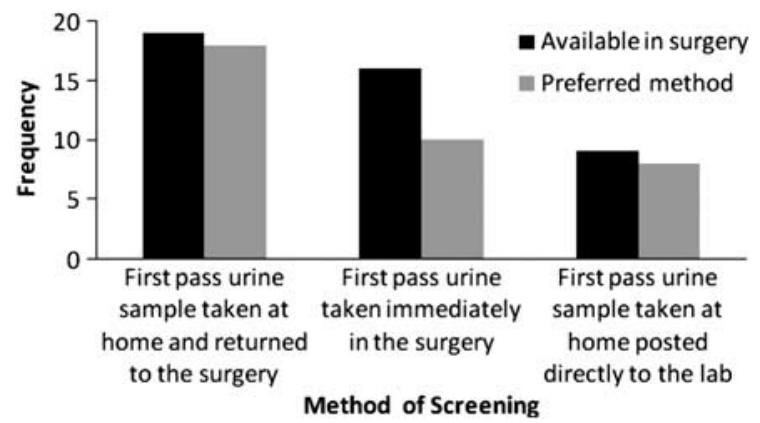

Graph 1 Preferred and available screening methods for men.

\section{Practice organisational variables}

We examined the participants' views of the organisational barriers and facilitators of the practice staff offering screens to the target group.

\section{Preferred and available methods of screening}

For men, 'First pass urine taken at home and returned to surgery' was the most available and most preferred method by practice staff (see Graph 1). For women, 'High vaginal swab taken at the surgery' was the most available and most preferred method (see Graph 2). However, there was no clear consensus on the overall preferred method for women. Two respondents also noted that they did not have access to chlamydia urine tests for female patients at their usual lab.

\section{Offer behaviour and types}

Most staff reported attempting to find out if the patient has ever been sexually active before offering a chlamydia screen $(n=44)$, and these data were likely to be recorded in the notes $(n=30)$. Of those who do check, the majority $(n=43)$ ask the patient directly, with only nine also checking the relevant clinical history in the notes.

Staff predominantly reported using the method of offering and collecting the screen within the consultation $(n=32)$. Table 1 provides the total frequency of responses for each of the offer types.

\section{Offer frequency}

Approximately half of the sample $(n=25)$ were able to estimate how many chlamydia screens they 


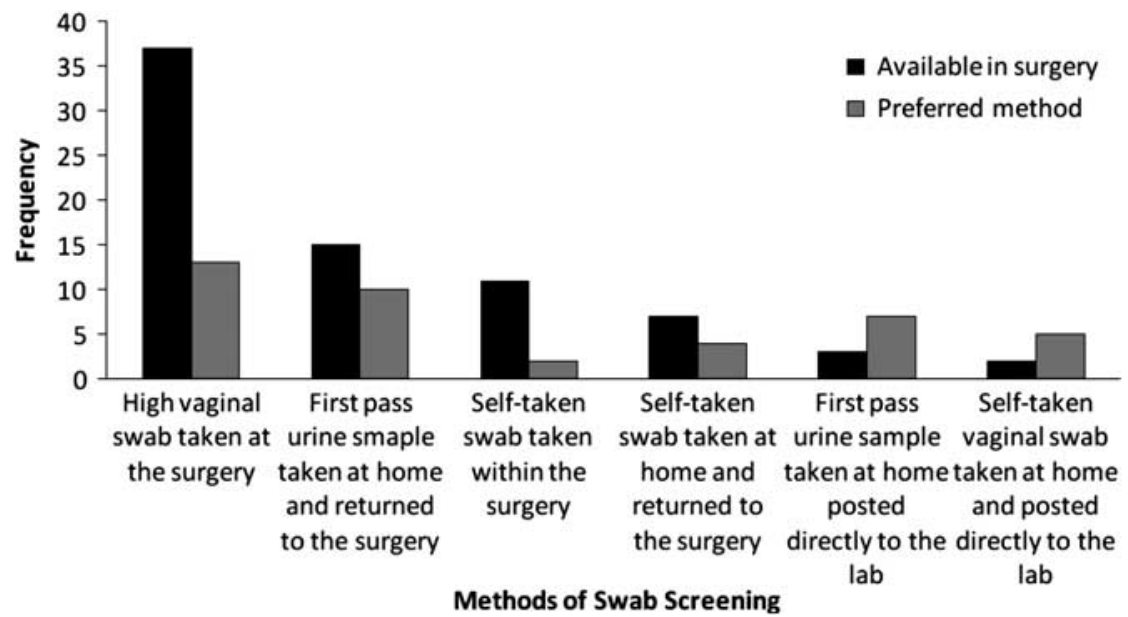

Graph 2 Preferred and available swab screening methods for women.

Table 1 Method for offering a chlamydia screen

\begin{tabular}{ll}
\hline Method & Frequency \\
\hline $\begin{array}{l}\text { Offer and collection of the screen within } \\
\text { the consultation }\end{array}$ & 32 \\
$\begin{array}{l}\text { Offer a leaflet and book another consultation } \\
\text { with General Practice nurse }\end{array}$ & 18 \\
$\begin{array}{l}\text { Offer a leaflet and offer to screen when } \\
\text { they next visit surgery }\end{array}$ & 12 \\
Offer a pack for them to take away & 10 \\
$\begin{array}{l}\text { Offer a pack for them to collect the } \\
\text { sample themselves within the surgery }\end{array}$ & 10 \\
$\begin{array}{l}\text { Only if patient requests screen } \\
\text { Make an appointment with the nurse }\end{array}$ & 2 \\
$\begin{array}{l}\text { Offer patient when they are having tests } \\
\text { for other sexually transmitted infections }\end{array}$ & 1 \\
\hline
\end{tabular}

had offered to 15-24 years old in the last month, with a mean response of four offers. Figures ranged from none $(n=2)$ to over $20(n=1)$.

General Practitioners and nurses were also asked if they offered a chlamydia screen to young people aged 15-24 years old in the following types of consultations:

- within a clinical consultation which is sexual health related,

- in services used specifically by young people,

- within any other clinical consultation.

Responses indicated a greater tendency to offer screens within sexual health consultations, with negligible offers in other types of consultations. Graph 3 illustrates this finding.

\section{Recording methods}

Results indicate limited staff knowledge of practice demographics and screening rates. Few respondents knew how many people aged 15-24 years old were registered at their practice, with only 14 able to provide a figure (ranging from 54 to 12600). Only seven felt able to estimate the percentage of those aged 15-24 years who have been offered a chlamydia screen in the surgery as a whole within the last year. Seven respondents were able to indicate the percentage of those screened opportunistically who had received a positive result, although figures ranged from $1 \%$ to an implausibly high $30 \%$.

There was also evidence of incomplete recording systems within the practices.

Data were collected primarily electronically $(n=44)$, and also less frequently by paper-based methods $(n=13)$. Only six said that the surgery recorded whether 15-24 years old were sexually active, and only just over half $(n=30)$ reported that their surgery has mechanisms for collecting the number of chlamydia samples sent for testing on people aged 15-24 years old. Only 16 respondents said that theses data were regularly reviewed or audited within the practice.

No respondent knew the correct percentage of the target group to be screened, which at the time of the survey was $17 \%$. Most stated that they did not know the target $(n=26)$, but those giving percentages were incorrect $(\mathrm{eg}, 10 \%, 20 \%, 70 \%$ and $80 \%$ ). 


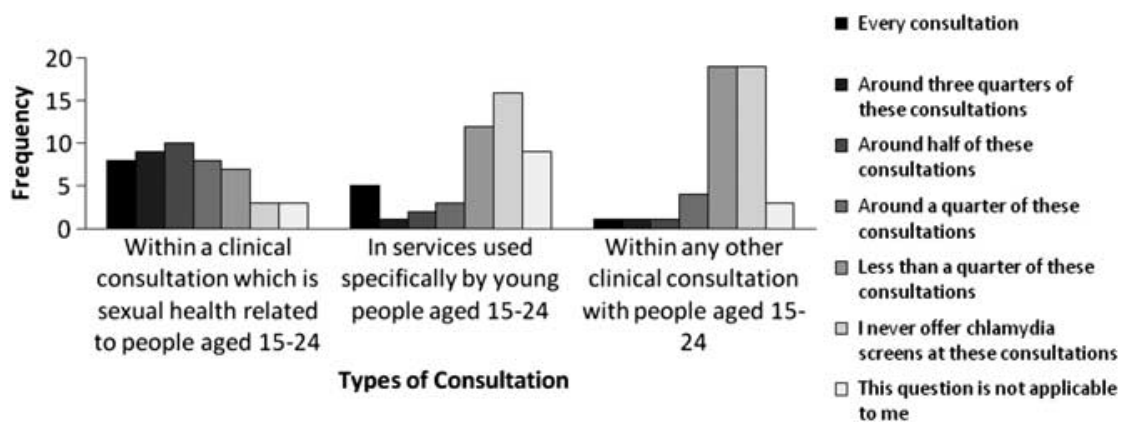

Graph 3 Frequency of offering chlamydia screen for different types of consultation.

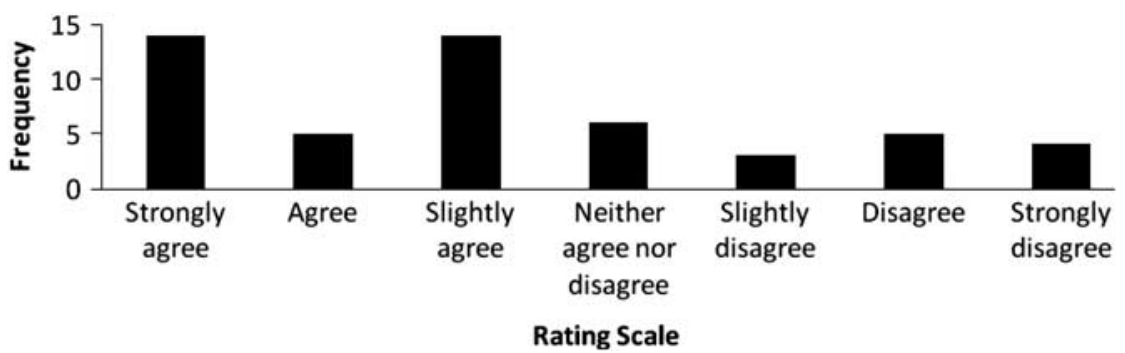

Graph 4 Intention to opportunistically screen target group.

\section{TPB item results}

\section{Intention}

Most respondents indicated a strong intention to opportunistically screen the target group. Most respondents either 'strongly agreed' $(n=14)$ or 'slightly agreed' $(n=14)$ with the intention statement. Of concern is the significant minority $(n=9)$ who 'disagreed' or 'strongly disagreed' with the statement, or who endorsed this item was not applicable to them $(n=18)$. Graph 4 illustrates these findings.

\section{Attitudes towards offering chlamydia screening}

The majority of participants showed some level of agreement (ie, from 'slightly agree' to 'definitely agree') with all of the advantages listed. 'Raising the awareness of chlamydia' $(n=32)$ and 'improving the care of patients' $(n=30)$ received the most 'definitely agree' ratings and only 'less work by tagging onto consultation' received a significant amount of disagreement with eight respondents reporting 'definitely disagree'.

The advantages of chlamydia screening were also highlighted in the initial interviews:

I think it's very advantageous because it's the commonest STI, the younger people under 25 are most at risk, and it can be completely asymptomatic, and it can cause PID, infertility problems and tubal problems and so it's very much in their best interest.

\section{General Practitioner}

In regard to the disadvantages, only 'problems arising around contact tracing' $(n=17)$ and 'additional time in consultation' $(n=15)$ received high levels of 'definitely agree' ratings. In many of the interviews, staff expressed confusion over whose role it was to conduct contract tracing and concern about the time and resources required if they had to do it.

I don't know that we have the resources or the time in general practice to actually do all 
of that contact tracing I would imagine that takes a hellish amount of time um but if that's not happening then how effective is the service? I suppose like us with everything it has a time and money implication.

Practice nurse

As shown in Table 2, respondents demonstrated various beliefs about the other disadvantages. For example, 10 respondents reported that they 'definitely disagreed' that screening being 'offensive for patient' was a disadvantage and 10 participants 'slightly agreed'. One respondent also identified the additional disadvantages of confidentiality concerns over contacting patients with results, and the need to ensure patients understand the implications of chlamydia for their health.

We also examined attitudes towards offering screens to those under the legal age of consent for sexual intercourse. All respondents agreed that screening behaviour should not be different for those aged 15 years old. In the interviews we found similarly supportive views:

\section{Age should not be a factor if risk is present}

It is important everyone is aware, whatever age

If sexually active, it's important to provide info, offer appropriate screening to allow informed choice

The responses to the open ended question about screening those less than 16 years old showed that all who commented had positive attitudes towards screening this group, with advantages including improved detection and treatment rates, reduction of long-term complications, helping to prevent pelvic inflammatory disease, early detection and education opportunities. However, one respondent also raised concerns over consent and competency issues, and one was also concerned about the invasiveness of questioning children on this topic.

\section{Social norm}

Most respondents felt that people and agencies that were influential regarding chlamydia screening for the target group would approve of opportunistic screening. Within the surgery, the most influential person on chlamydia screening for target group was expected to completely approve $(n=12)$, approve $(n=16)$ or slightly approve $(n=6)$. This influential person was identified through having a special interest or experience in sexual health, being concerned for patient welfare, and being generally supportive of staff, but not because of seniority. This was also reflected in the initial interviews with practice staff.

I think everyone would approve, and within the practice I can't think of anyone who wouldn't approve of it so long as it was optional. General Practitioner

However, six respondents indicated that the influential person would disapprove. Reasons given included concern about mentioning opportunistic screening within the practice, or believing that approval would be conditional on not incurring time or financial costs.

Beyond the practice, respondents believed that strong approval would come from the chlamydia co-ordinator $(n=38)$, Genitourinary Medicine (GUM) clinic $(n=34)$, schools and youth groups $(n=19)$, and the PCT $(n=22)$, with general approval from the population as a whole. Some respondents felt that the PCT $(n=5)$, GUM clinic $(n=3)$, and the co-ordinator $(n=1)$ would disapprove of the behaviour. Reasons for this include limited funding and resources onto which screening would add an additional strain.

\section{PBC}

Participants felt largely in control and confident about being able to offer a chlamydia screen to the target group. The majority of respondents strongly or slightly agreed with the statements relating to control, confidence, knowledge, and skills.

A small minority disagreed with the statements about control and confidence, while five respondents indicated having insufficient knowledge and skills. Graph 5 illustrates responses to this question.

\section{Facilitators and barriers}

Table 3 shows the perceived impact of the patients' circumstances on the ease with which respondents felt currently able to make offers (Table 3).

Presenting with a sexual health issue made it 'much easier' for staff to make an offer $(n=45)$, followed by attending for cervical screening $(n=33)$, attending for a contraceptive pill check 
Table 2 Participant agreement with potential advantages and disadvantages of screening

\begin{tabular}{|c|c|c|c|c|c|c|c|}
\hline & $\begin{array}{l}\text { Definitely } \\
\text { agree }\end{array}$ & Agree & $\begin{array}{l}\text { Slightly } \\
\text { agree }\end{array}$ & $\begin{array}{l}\text { Neither agree } \\
\text { nor disagree }\end{array}$ & $\begin{array}{l}\text { Slightly } \\
\text { disagree }\end{array}$ & Disagree & $\begin{array}{l}\text { Definitely } \\
\text { disagree }\end{array}$ \\
\hline \multicolumn{8}{|l|}{ Advantages } \\
\hline Raising awareness of chlamydia & 32 & 12 & 5 & 0 & 0 & 0 & 1 \\
\hline Improves the care of my patients & 30 & 11 & 5 & 3 & 0 & 1 & 0 \\
\hline Improve screening rate & 26 & 18 & 2 & 2 & 0 & 1 & 0 \\
\hline Reduce pelvic inflammatory disease & 26 & 19 & 2 & 1 & 0 & 1 & 0 \\
\hline Decrease infertility due to chlamydia & 25 & 17 & 5 & 1 & 0 & 0 & 1 \\
\hline Increased detection of positive cases & 25 & 16 & 6 & 1 & 0 & 1 & 0 \\
\hline $\begin{array}{l}\text { Opportunity to screen those who would not } \\
\text { otherwise come forward }\end{array}$ & 23 & 16 & 7 & 2 & 0 & 1 & 0 \\
\hline Makes screening acceptable/'the norm' & 22 & 19 & 3 & 2 & 0 & 1 & 0 \\
\hline Less work by tagging onto consultation & 6 & 10 & 6 & 9 & 5 & 4 & 8 \\
\hline \multicolumn{8}{|l|}{ Disadvantages } \\
\hline Additional time in consultation & 15 & 9 & 12 & 11 & 0 & 1 & 0 \\
\hline Problems arising around contact tracing & 17 & 10 & 9 & 7 & 3 & 2 & 1 \\
\hline Increase patient's anxiety & 8 & 10 & 11 & 7 & 4 & 5 & 3 \\
\hline $\begin{array}{l}\text { If positive result may need referral to } \\
\text { genitourinary medicine }\end{array}$ & 8 & 9 & 9 & 8 & 5 & 3 & 5 \\
\hline Patient is put under pressure & 7 & 9 & 9 & 10 & 6 & 2 & 6 \\
\hline Intrusive for patient & 6 & 11 & 9 & 7 & 10 & 2 & 4 \\
\hline Offensive for patient & 3 & 5 & 10 & 8 & 8 & 4 & 10 \\
\hline Unpleasant experience for the patient & 1 & 5 & 11 & 12 & 3 & 8 & 6 \\
\hline Patient will not be interested & 1 & 3 & 9 & 7 & 14 & 5 & 7 \\
\hline
\end{tabular}

Note: actual numbers of responses presented. 


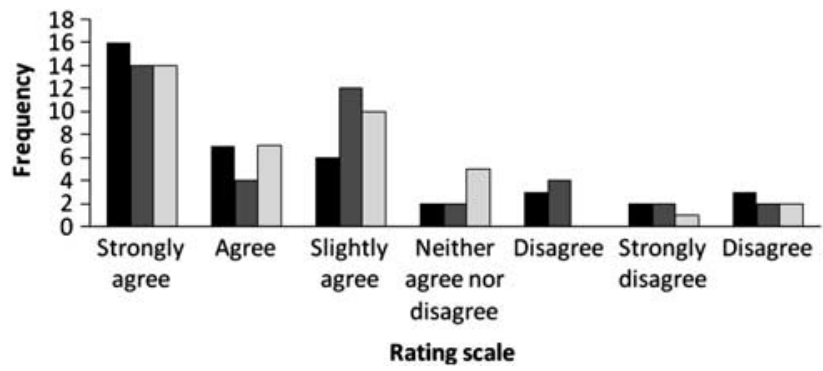

I feel I have full control over whether or not I offer a chlamydia screen to the target group in my surgery

I am confident that I can offer a chlamydia screen to the target group in my surgery

Graph 5 Reported level of control in offering chlamydia screens.

Table 3 Perceived impact of situations and circumstances on current offer behaviour

\begin{tabular}{|c|c|c|c|c|c|c|c|}
\hline Situations/circumstances & $\begin{array}{l}\text { Much } \\
\text { easier }\end{array}$ & Easier & $\begin{array}{l}\text { Slightly } \\
\text { easier }\end{array}$ & $\begin{array}{l}\text { No } \\
\text { impact }\end{array}$ & $\begin{array}{l}\text { Slightly } \\
\text { harder }\end{array}$ & Harder & $\begin{array}{l}\text { Much } \\
\text { harder }\end{array}$ \\
\hline Patient presents with a sexual health issue & 45 & 3 & 2 & 0 & 0 & 0 & 0 \\
\hline Patient attending for cervical screening & 33 & 8 & 4 & 2 & 1 & 0 & 0 \\
\hline Patient attending for contraceptive pill check & 22 & 13 & 5 & 5 & 1 & 1 & 1 \\
\hline Patient attending to obtain contraception & 20 & 13 & 8 & 3 & 3 & 1 & 0 \\
\hline Patient attending with friends & 5 & 5 & 5 & 16 & 7 & 6 & 4 \\
\hline Comprehension barriers & 0 & 0 & 1 & 6 & 20 & 8 & 13 \\
\hline $\begin{array}{l}\text { Patient presents with an issue unrelated to } \\
\text { sexual health }\end{array}$ & 8 & 1 & 2 & 6 & 10 & 15 & 17 \\
\hline Language barriers & 0 & 0 & 0 & 3 & 16 & 11 & 18 \\
\hline Patient attending with parents & 0 & 1 & 0 & 6 & 7 & 11 & 23 \\
\hline
\end{tabular}

$(n=22)$ or to obtain contraception $(n=20)$. In support of this we also found that a main theme in the initial interviews was that General Practitioners and nurses were much more likely to offer screens during sexual health, contraceptive or cervical screening consultations.

I guess if they are coming in with related problems like contraception and or low mood (but you then talk about relationships) they're the kind of consultations where I may well mention it.

\section{General Practitioner}

If they are coming in for contraception, emergency contraception, concerns about partners and what-have-you, then we would offer it as part of the consultation really.

Nurse

Presenting with an issue unrelated to sexual health $(n=17)$, presenting with parents $(n=23)$, language barriers $(n=18)$, and comprehension barriers $(n=13)$ made it 'much harder' to offer screens. Presenting with friends appeared to have 'no impact' $(n=16)$.

With respect to future offer behaviour, Table 4 shows that factors including the surgery signing up as a whole $(n=29)$, training on the benefits of screening $(n=28)$, and raising awareness of screening via well-displayed posters $(n=23)$ and leaflets $(n=21)$, would make offering screens 'much easier'. Conversely, lack of support by colleagues $(n=12)$ and patients being unwilling to talk about STIs $(n=14)$ would make it 'much harder'. Concerns over confidentiality $(n=12)$, offending patients $(n=21)$, and guidance on transporting samples $(n=17)$ reportedly had 'no impact'.

Graph 6 shows ratings of the importance of six barriers preventing staff from offering chlamydia screens. As the mean score of each of the barriers is over 5, they all appear to be important factors in preventing screens from being offered to the target group. The two highest rated barriers were 'Handling the issue when there are other family members present' $(M=6.27)$ and 'time within my consultations' $(M=5.94)$. In the interviews the 
Table 4 Perceived impact of circumstances on future offer behaviour

\begin{tabular}{lccccccc}
\hline Factors/circumstances & $\begin{array}{l}\text { Much } \\
\text { easier }\end{array}$ & Easier & $\begin{array}{l}\text { Slightly } \\
\text { easier }\end{array}$ & $\begin{array}{l}\text { No } \\
\text { impact }\end{array}$ & $\begin{array}{l}\text { Slightly } \\
\text { harder }\end{array}$ & Harder & $\begin{array}{l}\text { Much } \\
\text { harder }\end{array}$ \\
\hline If surgery signs up as a whole & 29 & 8 & 6 & 4 & 0 & 0 & 0 \\
Training on benefits of screening & 28 & 4 & 6 & 8 & 0 & 0 & 0 \\
Well-displayed posters in surgery & 23 & 16 & 6 & 2 & 1 & 0 & 0 \\
Knowledge about treatment & 24 & 10 & 6 & 6 & 1 & 0 & 1 \\
Leaflets easily available & 21 & 15 & 8 & 2 & 0 & 1 & 0 \\
Raising awareness of screening & 19 & 18 & 7 & 3 & 0 & 1 & 0 \\
Knowing how to deal with positive results & 18 & 15 & 7 & 6 & 0 & 1 & 0 \\
Consultation skills & 18 & 9 & 9 & 10 & 0 & 1 & 0 \\
Contact tracing & 16 & 9 & 3 & 10 & 2 & 1 & 5 \\
Information on accuracy of tests & 16 & 14 & 6 & 8 & 1 & 1 & 0 \\
Feeling patient may be offended & 1 & 0 & 2 & 21 & 11 & 4 & 5 \\
Guidance on how to transport samples & 10 & 7 & 11 & 17 & 0 & 1 & 0 \\
Confidentiality concerns & 11 & 10 & 0 & 12 & 6 & 4 & 3 \\
Time available in consultation & 10 & 4 & 4 & 7 & 8 & 5 & 8 \\
Patient unwilling to discuss sexually & 4 & 0 & 6 & 4 & 8 & 10 & 14 \\
transmitted infections & 2 & 1 & 2 & 9 & 10 & 11 & 12 \\
Not having support from colleagues & 2 & 1 & & & & & \\
\hline
\end{tabular}

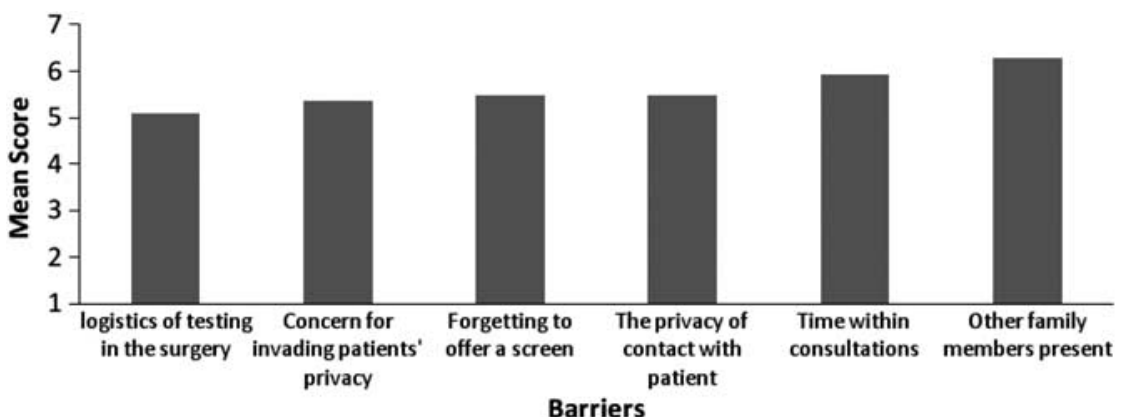

Graph 6 Reported importance of barriers to preventing staff from offering chlamydia screens to the target group.

issue of time was also expressed. A General Practitioner explained how offering a chlamydia screen required time to start the discussion and explain about the infection and the test.

I wouldn't feel uncomfortable doing it but it would be, the time constraints would stop me doing it I think.

\section{General Practitioner}

Just because you have to go in to open up the whole subject, very sensitively and finding out what is going on in their lives before you start saying do you want a chlamydia test so you must make sure the patient is aware of why they are having it done and what the implications of that are, you have got to be able to have the time to do that properly.

General Practitioner

\section{Differences in responses between GPs and nurses}

There were no significant differences (using $\chi^{2}$ and $t$-tests) between General Practitioners' and nurses' responses on any items. There was insufficient data to compare responses from receptionists.

\section{Discussion}

The limited number of interventions employed in other developed countries described above to 
increase chlamydia screening through targeting primary care staff to offer more screens to young people have mostly shown positive results. There are none to our knowledge that have explicitly employed psychological theory in the development of interventions for promoting the offer of chlamydia screens in primary care. The use the theory helps to explain why there are gaps between intention and reported practice, and suggest the specific attitudes that might be targeted to improve the intention to offer screens more reliably.

\section{TPB-related interventions}

Most of the participants intended to offer chlamydia screens and most reported feeling largely in control and confident about being able to offer a chlamydia screen to the target group. However, the low frequency of screening offers reported by respondents and the low screening rates of the practices as a whole indicates that intentions are not translating into actual behaviour. Interventions have been developed in other contexts which improve the execution of intentions by forming plans (Gollwitzer, 1999). Within an educative intervention staff would be asked to develop implementation intention' plans in relation to offering chlamydia screens to the target population. General Practice surgeries are the ideal site for offering screens as levels of chlamydia test positivity among young people are high here and in a qualitative study this group indicate that this is where they most want to be tested (Hogan et al., 2010). The intervention would support planning what to offer, when, with whom, and in what type of consultation.

Without performing a prospective study of the TPB constructs on behaviour at a subsequent time it is not possible to ascertain what level of prediction can be obtained using TPB constructs, and therefore how important they are likely to be as foci of interventions to increase screening offers. However, there is scope to target the intervention on TPB constructs that are potentially modifiable by an educative intervention. While staff attitudes about the benefits of screening were positive, respondents' beliefs about the disadvantages indicate a lack of knowledge about the procedure. For example, the majority of participants agreed that problems around contact tracing would be a disadvantage of increasing the offers of chlamydia screening.
However, the current procedure for contact tracing is that chlamydia test results are passed to local co-ordinators and it is then their role to contact previous sexual partners, with no involvement of the practice. If screening is to be embedded contractually in core services then the knowledge of local systems will become more important and the perceived barriers should be reduced.

With respect to social influences on offering chlamydia screens, the data indicated that not having support from colleagues would act as a barrier, and that the surgery signing up as a whole would facilitate staff to offer chlamydia screens. Some participants believed that the support they received would be conditional on not incurring time or financial costs. This indicates that practice staff would benefit from understanding what is expected of them by the surgery in terms of their resources and responsibilities for chlamydia screening.

\section{Consultation context}

A number of barriers and facilitators to offering screens to the target group were identified through the study, which relate to the consultation context. Staff reported that it was much easier to offer screens when patients presented for a sexual health consultation, compared with other consultations. This meant that offering screens is often confined to sexual health or family planning consultations. This will inevitably reduce the extent of opportunistic screening as such consultations are predominantly by females. Further, as services such as cervical screening are only available to women above the age of 25 years, they are again reducing opportunities to offer screens to the target population.

The large majority of staff attempted to find out if the patient has ever been sexually active before offering a chlamydia screen, and of these most report asking the patient directly and only a few checked the patients' notes. This is consistent with previous studies (Sripada et al., 2007). Therefore asking patients whether they are sexually active may act as a barrier to offering a screen and sexual health consultations eliminate this barrier as the information is already evident. Additionally, results showed that although the large majority found out if patients had been sexually active only a minority reported this information in the notes, which implies that patient notes are not being kept up to date with this type of 
behavioural information and so are not a reliable source in future consultations.

A practical recommendation for intervention to overcome this barrier is to design and implement a more comprehensive recording system for consultations with young people. This would include recording previous screens and offers of screens, although currently this cannot be Read coded and so would not be readily searched for. Staff can then be encouraged to monitor the data in these systems to assess achievements against targets. Also, as staff reported that computer prompts were not currently used in their practices, this system could also act as a reminder to doctors and nurses by prompting them during a consultation that the patient is suitable for chlamydia screening. It should be noted that chart prompts were not effective in a previous study in the United States (Scholes et al., 2006), however, this has not been trailed in the United Kingdom, and would be facilitated by having a more comprehensive recording system for consultations regarding sexual health of young people.

Staff also reported that receiving training on the benefits of screening and raising awareness of screening would make it easier to offer screens. These factors could easily be addressed through an education intervention to increase staff's knowledge of the benefits of screening and of screening guidelines. If combined with a patientfocused awareness campaign, this would act to increase the perception by staff that patients can expect to discuss chlamydia screening as a matter of routine, as suggested by a previous review of interventions (Ginige et al., 2007).

Increased time in consultations was reported as an important barrier to preventing staff from offering chlamydia screens. A future intervention could use video-taped vignettes of providing screening offers within the usual consultation duration.

It is unlikely any one single change will be effective, and the results of the TBP questions, alongside those related to organisational practices and offer behaviour, suggest there are several possible interventions, which could be combined in a comprehensive intervention aimed at the beliefs and behaviours of staff and overcoming modifiable organisational barriers. We suggest this may be more successful if an intervention fosters patient awareness campaigns to increase the receptiveness of patients to the offer of screens, and to indirectly address 'social norms' by signalling to patients and staff that offering screens is a routine practice.

From these results, we suggest several components of an integrated intervention:

- Staff education on the benefits of screening, and including plans to overcome barriers to screening in their personal practice.

- Staff-focused education to model effective offer skills in consultations and by other practice staff particularly receptionists.

- Organisation-focused interventions to improve data recording of sexual health and screening services offered and the results of screens, which should be regularly audited and reviewed for opportunities to target screening offers more effectively.

- Making available a full range of options for testing. Practices need to ensure, where possible, that in addition to the currently available vaginal swabs and urine tests, that patients are signposted to other sources so that their preferences are met which may increase uptake.

- Patient-focused interventions such as advertising the rationale for chlamydia testing within the surgery to increase young people's awareness and their readiness to seek and respond to offers of screening.

\section{Limitations}

The response rate to the questionnaire was low, and there was missing data on some items, particularly the TPB items where the question structure can appear to be repetitive. Some respondents commented that completing the questionnaire had elicited discussion within the practice, or raised the profile of screening to the individual. An increased awareness and discussion of chlamydia screening as generated through this survey is likely to lead to an increased number of screens being offered, this raises a potential issue to be considered when evaluating any intervention where the survey we have developed is used to assess change in attitudes and practices. Evaluations will be enhanced by comparing intervention practices with control surgeries.

\section{Acknowledgements}

We would like to thank all of the staff in the Warwickshire and Coventry surgeries involved for taking 
time to complete and return questionnaires, and Katie Elford for her administrative support.

\section{References}

Ajzen, I. 1985: From intentions to actions: a theory of planned behaviour. In Kuhl, J. and Beckman, J., editors, Action-control: from cognition to behaviour. Heidelberg: Springer, 11-39.

Ajzen, I. and Fishbein, M. 1980: Understanding attitudes and predicting social behaviour. Englewood Cliffs, NJ: Prentice Hall.

Boekeloo, B.O., Snyder, M.H., Bobbin, M., Burstein, G.R., Conley, D., Quinn, T.C. and Zenilman, J.M. 2002: Provider willingness to screen all sexually active adolescents for chlamydia. Sexually Transmitted Infections 78, 369-73.

Cook, R.L., Wiesenfeld, H.C., Asgton, M.R., Krohn, M.A., Zamborsky, T. and Scholle, S.H. 2001: Barriers to screening sexually active adolescent women for Chlamydia: a survey of primary care physicians. Journal of Adolescent Health 28, 204-10.

Department of Health. 2004: National Chlamydia Screening Programme (NCSP) in England: programme overview; core requirements; data collection, second edition. London: Department of Health.

Ginige, S., Fairley, C.K., Hocking, J.S., Bowden, F.J. and Chen, M.Y. 2007: Interventions for increasing Chlamydia screening in primary care: a review. BMC Public Health 7, 1-6.

Gollwitzer, P.M. 1999: Implementation intentions: strong effects of simple plans. American Psychologist 54, 493-503.

Hanbury, A., Wallace, L. and Clark, M. 2009: Use of a time series design to test effectiveness of a theory-based intervention targeting adherence of health professionals to a clinical guideline. British Journal of Health Psychology 14, 505-18.

Health Protection Agency. 2010: Number and rates of new chlamydia diagnoses made in the $U K$ and England: 2008-2010. London: Health Protection Agency. Retrieved 11 May 2010 from http://www.hpa.org.uk/web/HPAweb File/HPAweb_C/1281953080247

Hogan, A., Howell-Jones, R., Pottinger, E., Wallace, L.M. and McNulty, C. 2010: "They should be offering it": a qualitative study to investigate young peoples' views and knowledge about chlamydia screening in primary care. BMC Public Health 10, 616.

Low, N. 2007: Screening programmes for Chlamydia infection: when will we ever learn? British Medical Journal 334, 725-28.

McClure, J.B., Scholes, D., Grothaus, L., Fishman, P., Reid, R., Lindenbaum, J. and Thompson, R.S. 2006: Chlamydia screening in at-risk adolescent females: an evaluation of screening practices and modifiable screening correlates. Journal of Adolescent Health 38, 726-33.

McNulty, C.A.M., Freeman, E., Oliver, I., Ford-Young, W. and Randall, S. 2008a: Strategies used to increase Chlamydia screening in general practice: a qualitative study. Public Health 122, 845-56.

McNulty, C.A.M., Thomas, M., Bowen, J., Buckley, C., Charlett, A., Gelb, D., Foy, C., Sloss, J. and Smellie, S. 2008b: Interactive workshops increase chlamydia testing in primary care: a controlled study. Family Practice 25/4, 1460-2229.

National Audit Office (NAO). 2009: Young people's sexual health: the National Chlamydia Screening Programme. Report by the Comptroller and Auditor General. London: The Stationary Office.

National Chlamydia Screening Steering Group. 2006: New Frontiers. Annual report of the National Chlamydia Screening Programme in England 2005/06. London: Health Protection Agency.

Pimenta, J., Catchpole, M., Gray, M., Hopwood, J. and Randall, S. 2000: Evidence based health policy report. Screening for genital Chlamydial infection. British Medical Journal 321, 629-31.

Scholes, D., Grothaus, L., McClure, J., Reid, R., Fishman, P., Sisk, C., Lindenbaum, J.E., Green, B., Grafton, J. and Thompson, R.S. 2006: A randomised trial of strategies to increase chlamydia screening in young women. Preventive Medicine 43, 343-50.

Sripada, S., Logan, S., McGillivray, S., Templeton, A., Hamilton, M., Sutherland, A. and Bhattacharya, S. 2007: Opportunistic screening for Chlamydia Trachomatis in men attending three different secondary healthcare settings. Sexually Transmitted Infection 83, 282-85. 